\title{
COMPARISON OF SOCIODEMOGRAPHIC AND CLINICAL VARIABLES IN SCHIZOPHRENICS WITH AND WITHOUT SUBSTANCE ABUSE
}

\author{
Manjunath Rajashekharaiah ${ }^{1}$, Pravin Verma²
}

1 Junior Resident, Department of Psychiatry, Shimoga Institute of Medical Sciences, Shimoga.

${ }^{2}$ Senior Resident, Department of Psychiatry, Indira Gandhi Government Medical College and Hospital, Nagpur.

\section{ABSTRACT}

\section{BACKGROUND}

Substance abuse is associated with poor outcome in schizophrenia patients. Alcohol and cannabis were reported to be most commonly abused substances in schizophrenics. Great care is needed to manage these patients. Sociodemographic and clinical data from India is sparse and therefore the need for this study.

\section{MATERIALS AND METHODS}

Patients who gave written informed consent and met inclusion and exclusion criteria were taken into study. They were administered sociodemographic proforma, clinical profile sheet, and substance abuse proforma. Data was subjected to statistical analysis.

\section{RESULTS}

Mean age of substance abusers was 27.96 yrs. and of non-abusers group was 32.68 yrs. Non-abusers group had a later age of onset of schizophrenia compared to the substance abusers group (mean age at onset: 25.56 vs. 22.88 yrs.). Duration of schizophrenia in substance abusers was shorter compared to non-abusers (mean duration in months: 65.00 vs. 89.88). Onset of schizophrenia was acute in 2 and insidious in 21 patients of non-abusers group. Commonest subtype of schizophrenia was paranoid in 18 and 20 among substance abusers and non-abusers respectively. Family history of substance abuse was present in 12 substance abusers as compared to only 3 of non-abusers. Among substance abusers $60 \%$ abused alcohol, $28 \%$ cannabis, $28 \%$ opioids, and $16 \%$ were polysubstance abusers. Alcohol abuse had a later age of onset than both cannabis and opioids.

\section{CONCLUSION}

Substance abusing schizophrenics were younger than non-abusing. $60 \%$ of patients had completed middle school and more than half had semiskilled jobs. Majority were married. Substance abusers had earlier onset and shorter duration of schizophrenia than non-abusers. Most patients had paranoid schizophrenia and insidious onset of illness. Alcohol was commonest abused substance. Age of onset for alcohol abuse was higher than that for cannabis.

\section{KEYWORDS}

Schizophrenia, Substance Abuse, Clinical Variable, Alcohol.

HOW TO CITE THIS ARTICLE: Rajashekharaiah M, Verma P. Comparison of sociodemographic and clinical variables in schizophrenics with and without substance abuse. J. Evolution Med. Dent. Sci. 2016;5(66):4681-4686, D0I: 10.14260/jemds/2016/1067

\section{INTRODUCTION}

Substance of abuse can produce symptoms that resemble those of schizophrenia. They can jeopardise management by their pharmacokinetic interactions. This comorbidity is associated with poor treatment compliance, increased rates of relapse, disruption of role functioning and greater burden..$^{1,2}$ Understanding the psychopathology of organic mental disorders like substance abuse will help understand the psychopathology of schizophrenia.,4 Rate of substance abuse among schizophrenics is twice that of general population. ${ }^{5}$ They usually receive partial care in either a psychiatric clinic or a de-addiction centre. 6 So, when a substance abusing schizophrenic patient is to be treated, great care is warranted in understanding antecedent causes and risk behaviour. ${ }^{2}$ Research in this important subset of schizophrenic patients is, however, fraught with many methodological problems and difficulties and therefore remain inconclusive. ${ }^{7}$

Financial or Other, Competing Interest: None.

Submission 24-07-2016, Peer Review 05-08-2016,

Acceptance 08-08-2016, Published 16-08-2016.

Corresponding Author:

Manjunath Rajashekharaiah,

\#404, Staff Quarters,

District MCGANN Hospital Compound,

SIMS, Shimoga-577201.

E-mail:docmatic@gmail.com

DOI: $10.14260 /$ jemds/2016/1067

\section{MATERIAL AND METHODS}

\section{AIMS AND OBJECTIVES}

To compare substance-abusing schizophrenics with nonsubstance abusing schizophrenics on specified demographic and clinical variables.

The sample was drawn from patients attending the outpatient clinic of at Vijayawada Institute of Mental Health and Neurosciences Hospital, Vijayawada. The sample consists of

1. 25 schizophrenics who did not abuse psychoactive substances and

2. 25 schizophrenics who fulfilled criteria for psychoactive substance abuse.

The patients in the sample were consecutive and were subjected to the following inclusion and exclusion criteria.

\section{Inclusion Criteria}

- A definitive clinical diagnosis of schizophrenia as per ICD10.

- Schizophrenic syndrome presented either preceding substance abuse or persisting for at least 2 weeks of substance-free state.

- The substance abusing group in addition fulfilled ICD-10 diagnostic criteria of substance abuse and dependence.

- The patients of both groups received equivalent doses of 
neuroleptic therapy.

- The patients of age between 18-55 yrs. were taken.

\section{Exclusion Criteria}

- Patient who has substance-induced psychoses.

- Patients who in addition suffered from mental retardation.

- Uncooperative patients (e.g. mute, severe formal thought disorder preventing meaningful communication).

\section{Instruments}

1. Sociodemographic Proforma: This proforma recorded patient's information regarding age, marital status, occupation, education, income, religion, family type, and locality of residence.

2. Clinical Profile Sheet: It recorded clinical details of patients, viz. age at onset of schizophrenia, onset type, duration of total illness, type of schizophrenia, and family.

3. Substance Abuse Proforma: Used for collecting information regarding substance abuse. It consists of type of drug, age at onset, duration of abuse, current amount and frequency, last use and family history of substance abuse.

\section{Procedure for Study}

Patients who gave written informed consent and met the inclusion and exclusion criteria were taken into the study on consecutive basis without any deliberate matching for specified clinical and sociodemographic variables except that they were on equivalent doses of neuroleptics. The two groups of consecutive patients fulfilling the criteria for study were administered the above-mentioned instruments. The patients were examined over or two sittings along with at least one family member to ensure reliability of information. The data thus generated was subjected to appropriate statistical analysis to meet the aims and objectives of the study.

\section{Ethical Considerations}

Throughout the study, ethical considerations were observed by taking informed consent ensuring confidentially. Ensuring that treatment was not compromised in anyway by the study and not carrying out any invasive investigations.

\section{Review of Literature}

The reported rates of prevalence of substance abuse among the psychiatric patients vary from $15-65 \%$ for schizophrenics and major depressives, $50 \%$ for bipolar patients, and $21-32 \%$ for anxiety disorder patients.8,9 The term 'dual diagnosis patient' and 'mentally ill chemical abusers or MICA' have been coined to describe patients with co-existent mental illness and substance abuse.

\section{Prevalence of Substance Abuse in Schizophrenics}

Substance abuse has been recorded in $52 \%$ of schizophrenics consecutively admitted to psychiatric hospital. ${ }^{10}$ Further a life time prevalence of drug dependence was found in $36.8 \%$ of schizophrenics. ${ }^{11}$ In another recent study in a sample of 205 psychiatric inpatients $76 \%$ of men and $34 \%$ of women admitted use of substance. Of the current users, $61.8 \%$ were schizophrenics. ${ }^{12}$ These studies involve people in treatment for schizophrenia. Epidemiological data from the Epidemiologic Catchment Area (ECA) study in the USA recorded a lifetime prevalence rate of $47 \%$ for substance abuse in schizophrenia compared to $87 \%$ in antisocial personality disorder, $56 \%$ in bipolar disorder, and $32 \%$ in depressive disorder. ${ }^{13}$

\section{Pattern of Substance Abuse in Schizophrenics}

Alcohol is the most common substances of abuse among schizophrenics.8,14,15 Some studies found Cannabis as the predominantly abused substance.16,17 The most commonly used combination of drugs was alcohol and cannabis. Cocaine, opiates, and sedatives were the other substances. But, psychiatric diagnosis was not related to the abuse of different classes of substance. Substance abuse was much more prevalent in the more "chronic" patients.9,18

As regards substance abuse in schizophrenia, the available literature from India is sparse. In a general population study, $13.69 \%$ of schizophrenics were found to use drugs as compared to $16.33 \%$ of manic depressive patients and $2.21 \%$ of normal population. ${ }^{19}$ Only 79 of 480 schizophrenics (16.5\%) abused drugs, mainly alcohol or cannabis in another study. ${ }^{20}$ No study in India has focused on reasons for drug abuse or perceived effect of substances in schizophrenia.

\section{AETIOLOGY}

Aetiology of Substance Abuse in Schizophrenia Revolves Mainly Around 4 'Models' as Follows

1. The Two stage model posits that schizophrenics with better premorbid adjustment are more sociable and, therefore, more exposed to opportunities of substance abuse. Subsequent onset of psychosis accelerates the use to a pathological level as the individual attempts to cope with the stress of the developing mental illness. ${ }^{21}$

2. The Vulnerability Model hypothesizes that drug abuse may cause schizophrenia or increase the likelihood of its expression in an already vulnerable individual. 22 It is derived from early observations of the psychotogenic properties of many substances of abuse.18,23-26 Increased vulnerability to addictive behaviour may reflect the effect of pathogenesis of schizophrenia on the neural circuitry mediating drug reward and reinforcement. Thus, schizophrenic patients may have a predilection for addictive behaviour as a primary disease symptom in parallel to and in many cases independent from their other symptoms. ${ }^{27}$

3. The Self-Medication Model postulates that drug abusing schizophrenic patients maybe self-medicating their symptoms. ${ }^{28}$ Some stimulant drugs produce improved functioning and reduced symptoms in some patients and interestingly some schizophrenic patients may preferentially abuse stimulant. ${ }^{29}$ They are taken as they counteract distressing negative symptoms or neuroleptic-induced akathisia.30,31 Cocaine has been reported to reduce negative symptoms while cannabis increased positive symptoms of schizophrenia. ${ }^{30,32}$

4. The Independence Model suggests that determinants of substance abuse in schizophrenia may not differ from those in general population. Alcohol and cocaine abusers reported that their drug of choice induced aggravation of schizophrenic symptoms, but they still continued to take drugs. This is against self-medication. However, comorbid heroin abusers reported heroin-induced improvement of schizophrenic symptoms. Hence for opiates, there is support for self-medication. 33 Another 
study in schizophrenics did not find any link between specific substance use and specific symptoms. ${ }^{15}$ Also, the reasons for drug use reported by the schizophrenic and non-schizophrenic subjects are similar. ${ }^{34}$

Comparison between substance abusing and substance non-abusing schizophrenics (substance abusers and nonabusers).

Age: Co-morbid patients have been reported to be younger in most studies. $68 \%$ of co-morbid patients were below 40 years as compared to $48 \%$ of non-abusers. 35 Other studies also reported a younger age in substance abuse schizophrenics as compared to substance non-abusing schizophrenics.9,16,36

Marital Status: $70-71 \%$ of substance abusers were found to be single/unmarried as compared to $59 \%$ of non-abusers. ${ }^{35,37}$ Schizophrenic subjects with current or lifetime diagnosis of substance abuse/dependence to be predominantly single males with higher rates of criminal charges. ${ }^{38}$

Age at onset of schizophrenia: Early age of onset for substance abusers have been reported.24,37 However, those patients who had a past history of substance misuse had a significantly earlier age of onset for schizophrenia than those with no substance use. 39,40
Education: Statistically significant lower educational achievement was seen in co-morbid patients. ${ }^{40,41,42}$

Employment: Only 11\% of substance abusers group were employed. ${ }^{30}$

Premorbid Adjustment: Substance abusers have better premorbid adjustment prior to the onset of schizophrenia as described earlier. 21

Duration of Schizophrenia: Mean duration of schizophrenia in substance abusers was shorter than non-abusers in an older study. 43

Family History of Substance Abuse: Families of substance abusers were found to have more prevalence of substance abuse than those of non-abusers. 37

Substance of Abuse: Alcohol was the most common substance abused and the most common combination of substances abused were alcohol and cannabis. $8,14,38$

Age of Onset of Substance Abuse: Cannabis abuse was started at an earlier age than that of alcohol in previous studies. ${ }^{40,44}$

\section{RESULTS}

\begin{tabular}{|c|c|c|c|}
\hline Variables & Substance Abusers (N=25) & Non-Abusers $(\mathrm{N}=25)$ & t/X2 Value \\
\hline Age Mean & 27.96 & 32.68 & $t=2.01$ \\
\hline S.D. & 7.72 & 8.85 & N.S. \\
\hline \multicolumn{4}{|l|}{ Marital Status } \\
\hline Married & 16 & 18 & \multirow{3}{*}{$\begin{array}{l}\mathrm{X} 2=1.14 \\
\quad \text { N.S. }\end{array}$} \\
\hline Unmarried & 7 & 4 & \\
\hline Others & 2 & 3 & \\
\hline \multicolumn{4}{|l|}{ Education } \\
\hline$<6$ yrs. & 5 & 6 & \multirow{3}{*}{$\begin{array}{l}\mathrm{X} 2=0.13 \\
\quad \text { N.S. }\end{array}$} \\
\hline $7-12$ yrs. & 15 & 14 & \\
\hline $7-13>$ yrs. & 5 & 5 & \\
\hline \multicolumn{4}{|l|}{ Occupation } \\
\hline Semiskilled/Unskilled & 13 & 13 & \multirow{3}{*}{$\begin{array}{l}\mathrm{X} 2=0.75 \\
\quad \text { N.S. }\end{array}$} \\
\hline Student & 5 & 3 & \\
\hline Unemployed & 7 & 9 & \\
\hline \multicolumn{4}{|l|}{ Family Type } \\
\hline Nuclear & 8 & 8 & \multirow{3}{*}{$\begin{array}{l}\mathrm{X} 2=0.15 \\
\quad \text { N.S. }\end{array}$} \\
\hline Joint & 5 & 4 & \\
\hline Three Generation & 12 & 13 & \\
\hline \multicolumn{4}{|l|}{ Religion } \\
\hline Hinduism & 22 & 22 & $\mathrm{X} 2=0$ \\
\hline Islam & 3 & 3 & N.S. \\
\hline \multicolumn{4}{|l|}{ Residence } \\
\hline Urban & 15 & 13 & $\mathrm{X} 2=0.32$ \\
\hline Rural & 10 & 12 & N.S. \\
\hline \multicolumn{4}{|c|}{$\begin{array}{c}\text { Table 1: Comparison Between Substance Abusers and Non-Abusers in } \\
\text { Schizophrenia Across Sociodemographic Variables }\end{array}$} \\
\hline
\end{tabular}

N.S. - Nonsignificant

As shown in the Table 1, mean age of substance abusers group at the time of interview was 27.96 yrs. and that of non-abusers group was 32.68 yrs. Overall, the sociodemographic profile of the two groups was similar and there was no significant difference between the two groups. 


\begin{tabular}{|c|c|c|c|c|}
\hline Variables & & Substance Abusers $(\mathrm{N}=25)$ & Non-Abusers $(\mathrm{N}=25)$ & t/X2 value \\
\hline Age at the Onset of Schizophrenia (in yrs.) & $\begin{array}{l}\text { Mean } \\
\text { S.D. }\end{array}$ & $\begin{array}{c}22.88 \\
6.00\end{array}$ & $\begin{array}{c}25.56 \\
5.87\end{array}$ & $\begin{array}{l}\mathrm{t}=1.59 \\
\text { N.S. }\end{array}$ \\
\hline Duration of Schizophrenia (in months) & $\begin{array}{l}\text { Mean } \\
\text { S.D. }\end{array}$ & $\begin{array}{l}65.00 \\
42.32 \\
\end{array}$ & $\begin{array}{l}89.88 \\
70.09 \\
\end{array}$ & $\begin{array}{l}\mathrm{t}=1.52 \\
\text { N.S. }\end{array}$ \\
\hline Onset & $\begin{array}{c}\text { Abrupt } \\
\text { Acute } \\
\text { Insidious }\end{array}$ & $\begin{array}{l}0 \\
2 \\
3 \\
\end{array}$ & $\begin{array}{c}1 \\
3 \\
21 \\
\end{array}$ & $\mathrm{X} 2=1.29$ N.S. \\
\hline Type of Schizophrenia & $\begin{array}{c}\text { Paranoid } \\
\text { Undiffer } \\
\text {-entiated } \\
\text { Others }\end{array}$ & $\begin{array}{c}18 \\
4 \\
3\end{array}$ & $\begin{array}{c}20 \\
3 \\
2\end{array}$ & $\mathrm{X} 2=0.45 \mathrm{~N} . \mathrm{S}$. \\
\hline Family History of Schizophrenia & $\begin{array}{l}\text { Present } \\
\text { Absent }\end{array}$ & $\begin{array}{c}9 \\
16 \\
\end{array}$ & $\begin{array}{c}8 \\
17 \\
\end{array}$ & $\mathrm{X} 2=0.09$ N.S. \\
\hline Family History of Substance Abuse & $\begin{array}{l}\text { Present } \\
\text { Absent }\end{array}$ & $\begin{array}{l}12 \\
13\end{array}$ & $\begin{array}{c}3 \\
22\end{array}$ & $\begin{array}{c}\mathrm{X} 2=7.71 \\
\mathrm{p}=<0.01 \\
\text { significant }\end{array}$ \\
\hline
\end{tabular}

As shown in Table 2, the non-abusers group had a later age of onset of schizophrenia compared to the substance abusers group (mean age at onset: 25.56 vs. 22.88 yrs.). The duration of schizophrenia in the substance abusers group was shorter compared to the non-abusers group (mean duration in months: 65.00 vs. 89.88). The onset of schizophrenia was acute in 2 and insidious in 21 patients of non-abusers group. The common subtype of schizophrenia was paranoid - 18 and 20 patients in substance abusers and non-abusers group respectively. The family history of substance abuse was present in 12 substance abusers patients as compared to only 3 of non-abusers group.

Thus, overall the substance abusers and non-abusers groups were comparable across clinical variables of schizophrenia except for the substance abusers group having significantly more positive family history of substance abuse.

\begin{tabular}{|c|c|c|c|}
\hline Substances of Abuse & No. & $\%$ & $\begin{array}{c}\text { Age at Onset } \\
\text { Mean } \pm \text { S.D. }\end{array}$ \\
\hline Alcohol & 15 & 60 & $20.14 \pm 4.14$ \\
\hline Cannabis & 7 & 28 & $18.73 \pm 4.81$ \\
\hline Opioids & 7 & 28 & $18.17 \pm 4.89$ \\
\hline \multicolumn{4}{|c|}{$\begin{array}{c}\text { Table 3: No. and Percentage of Substances Taken by } \\
\text { Substance Abusing Schizophrenics }(N=25) \text { Along with } \\
\text { the Age of Onset of Substance Abuse }\end{array}$} \\
\hline
\end{tabular}

- The percentage calculations are based on $\mathrm{N}=25$, hence add up to more than $100 \%$.

- Four patients (16\%), abusing polysubstances ( 3 patients of alcohol + cannabis and 1 patient of alcohol + opioid) are included in the Table.

Table 3 shows that the substance abusers group was abusing alcohol, cannabis, and opioids. The most common substances of abuse in substance abusers group in this study were alcohol (60\%), followed by cannabis (28\%), and opioids (28\%) with equal frequency. $4(16 \%)$ patient were polysubstance abusers. Alcohol abuse had a later age of onset than both cannabis and opioids.

\section{DISCUSSION}

The mean age of substance abusing schizophrenic group was less than the mean age of substance non-abusing schizophrenic group (substance abusers $=27.96$ yrs. $<$ nonabusers $=32.68 \mathrm{yrs}$.). This is in agreement to the general trend that the substance abusers patients are younger compared to non-abusers patients. ${ }^{9,24,35,41}$ In an exception to this trend, a study of reported non-abusers patients to be younger (substance abusers $=27<$ non-abusers $=29$ ) a finding attributable to sampling bias in that the sample comprised of inpatients. ${ }^{45}$ The finding of lower age of substance abusers group can be due to dual diagnosis patients seeking early treatment due to more serious nature of problem, increased awareness, better social adjustment, and less psychopathology compared to non-abusers group.

$60 \%$ of patients of both the groups in our study had completed their middle school. This is in keeping with the literature where $61-78 \%$ of the patients are reported to have completed high school education. ${ }^{35,37}$ A slightly low level of achievement, middle school compared to high school, maybe due to general low level of educational attainment prevalent in our area.

In both the study groups, more than half of the patients were employed in semiskilled jobs (shopkeeper, farming, service, etc.) and were earning. This finding is in contrast to other studies where a majority in both groups of patients was unemployed. ${ }^{35,37}$ This could be explained by higher levels of tolerance of our society towards their illness or a lower severity of psychopathology.

Majority of our study group patients were married and living with the family. This is in contrast to the general trend in the literature, which reports that most of the schizophrenics with or without substance abuse are single and living alone. $26,35,38$

Again this could be attributed to the culture of marriage at an early age higher jointedness of the family prevalent in this region. These factors may be contributing, in part, to most of our patients continuing to be employed despite their behavioural problems.

The religion and residence of the study group is in keeping with the profile of the population in the catchment area of our hospital.

We found that the substance abusers patients of our study group had less mean age at onset of schizophrenia compared to the non-abuser patients (22.88 yrs. vs. 25.56 yrs.). This finding conforms to most other studies. ${ }^{24,37,39,40}$ This may be due to substance abuse acting as a stressor and precipitating schizophrenia in an already vulnerable individual.

We also found that mean duration of schizophrenia in substance abusers group was shorter than in the non-abusers 
group (65.0 month vs. 89.88). This is similar to the findings of another study (64 months vs. 78 months). ${ }^{43}$ The early attendance of substance abusers group at our outpatient clinic could either mean a greater severity of problem behaviours (forcing early treatment seeking) or a better insight or adjustment (encouraging treatment seeking) or more social support being available.

In only 4 co-morbid patients, schizophrenia preceded onset of substance abuse with vice versa in 21 patients. There were no differences in type of substances abused, age at intake, onset, and other variables in those 4 cases. Neither the reasons for drug abuse varied significantly between them and the other 21 cases.

Most of the patients of both the groups belonged to the paranoid subtype and had an insidious onset of illness.

We discovered that the family history of substance abuse was significantly high in substance abusers than in nonabusers. This suggests that there may be familial determinants of substance abuse, which could be environmental, genetic, or both. Similar findings have been reported by another. ${ }^{37}$ Substance abusers and non-abusers group did not differ across family history of schizophrenia. This suggests that compared to schizophrenia substance abuse has a greater potential for familial transmission.

Alcohol was abused by majority (60\%) of the substance abusers group. This conforms to the findings of other studies of similar nature (52.2 to $77.3 \%$ ). ${ }^{8,38}$ The most frequent abuse combination was alcohol and cannabis in a previous study, which again conforms to our finding of $75 \%$ of our polysubstance abusers abusing alcohol and cannabis. ${ }^{14} \mathrm{~A}$ high alcohol may be due to its easy availability, legal sanction, and less social stigma attached to its use compared to other drugs.

One study suggested that opioid abuse maybe underrepresented in the clinical samples due to their effectiveness as antipsychotics. 46

Age of onset of alcohol abuse (mean=19.63 yrs.) was higher than the age of onset of cannabis (mean=18.75 yrs.) and opioids (mean=18.67 yrs.). This agrees with other studies done recently. ${ }^{40,44}$ Since the current study focused on drugs of abuse likely to produce symptoms similar to schizophrenia, nicotine abuse was not given special attention to. It is one of the limitations of this study.

\section{SUMMARY AND CONCLUSION}

The mean age of substance abusing schizophrenic group was less than the mean age of substance non-abusing schizophrenic group. $60 \%$ of patients of both the groups in our study had completed their middle school. In both the study groups, more than half of the patients were employed in semiskilled jobs. Majority of the study group patients were married and living with family. The religion and residence of the study group was in keeping with the profile of the population in the catchment area of the hospital. Substance abusers had less mean age at onset of schizophrenia compared to the non-abuser patients. Mean duration of schizophrenia in substance abusers group was shorter than in the non-abusers group (65.0 month vs. 89.88). Most of the patients of both the groups belonged to paranoid subtype and had an insidious onset of illness. Family history of substance abuse was significantly high in substance abusers than in non-abusers. Alcohol was abused by majority $(60 \%)$ of the substance abusers group. The most frequent substance abuse combination was alcohol and cannabis. Age of onset of alcohol abuse (mean=19.63 yrs.) was higher than the age of onset of cannabis (mean=18.75 yrs.) and opioids (mean=18.67 yrs.).

\section{REFERENCES}

1. Bellack AS, Gearon JS. Substance abuse treatment for people with schizophrenia. Addict Behav 1998;23(6):74966.

2. Samuel SG. Pharmacological treatment of substanceabusing schizophrenic patients. Schizophrenia Bulletin 1990;16(1):111-22.

3. Liberman JA, Kinon BJ, Loebel AD. Dopaminergic mechanisms in idiopathic and drug-induced psychoses. Schizophrenia Bulletin 1990;16(1):97-110.

4. Aghajanian GK, Marek GJ. Serotonin model of schizophrenia: emerging role of glutamate mechanisms. Brain Research Reviews 2000;31(2-3):302-12.

5. Hambercht M, Hafner H. Do alcohol or drug abuse induce schizophrenia? Nervenarzt 1996;67(1):36-45.

6. Liberman JA, Bowers MB. Substance abuse comorbidity in schizophrenia: editor's introduction. Schizophrenia Bulletin 1990;16(1):29-30.

7. Smith J, Hucker S. Schizophrenia and substance abuse. British Journal of Psychiatry 1994;165(1):13-21.

8. Lehman AF, Myers CP, Corty E, et al. Prevalence and patterns of 'dual diagnosis' among psychiatric in-patients. Comprehensive Psychiatry 1994;35(2):106-12.

9. Mueser KT, Yarnold PR, Bellack AS. Diagnostic and demographic correlates of substance abuse in schizophrenia and major affective disorder. Acta Psychiatrica Scandinavica 1992;85(1):48-55.

10. Caton CL, Gralnick A, Bender S, et al. Young chronic patients and substance abuse. Hospital Community Psychiatry 1989;40(10):1037-40.

11. Ananth J, Vandewater S, Kamal M, et al. Missed diagnosis of substance abuse in psychiatric patients. Hospital Community Psychiatry 1989;40(3):297-9.

12. Ahmadi J, Fakoor A, Pezeshkian P, et al. Substance abuse among Iranian psychiatric in patients. Psychological Reports 2001;89(2):363-5.

13. Reiger DA, Farmer ME, Rae DS, et al. Co-morbidity of mental disorders with alcohol and other drug abuse. Results from the epidemiological catchment area (SCA) study. Journal of American Medical Association 1990;264(19):2511-8.

14. Lambert M, Hassen C, Mass R, et al. Consumption patterns and motivation for use of addictive drugs in schizophrenic patients. Psychiatrische Praxis 1997;24(4):185-9.

15. Cuffel BJ, Heithoff KA, Lawson W. Correlates of patterns of substance abuse among patients with schizophrenia. Hospital Community Psychiatry 1993;44(3):247-51.

16. Verdoux H, Mury M, Bensancon G, et al. Comparative study of substance dependence co-morbidity in bipolar, schizophrenic, and schizo-affective disorders. Encephale 1996;22(2):95-101.

17. DeQuardo JR, Carpenter CF, Tandon R. Patterns of substance abuse in schizophrenia: nature and significance. Journal Psychiatric Research 1994;28(3):267-75.

18. Soyka M. Alcohol-induced hallucinations. Clinical aspects, pathophysiology and therapy. Nervenartz 1996;67(11):891-5. 
19. Dube KC, Handa SK. Drug use in health and mental illness in an Indian population. British Journal of Psychiatry 1971;118:345-6.

20. Trivedi JK, Sethi BB. Drug abuse in psychiatric patients. Indian Journal of Psychiatry 1978;21:345-8.

21. Arndt S, Tyrrell G, Flaum M, et al. Comorbidity of substance abuse and schizophrenia: the role of premorbid adjustment. Psychological Medicine 1992;22(2):379-88.

22. Bowers MB. The role of drugs in the production of schizophreniform psychoses and related disorders. In: Meltzer HY, ed. Psychopharmacology. The third generation of progress. New York: Raven 1987:819-23.

23. Sato M, Numachi Y, Hamamura T. Relapse of paranoid psychotic state in methamphetamine model of schizophrenia. Schizophrenia Bulletin 1990;16(1):111-22.

24. Linszen DH, Dingemans PM, Lenior ME. Cannabis abuse and the course of recent onset schizophrenic disorders. Archives of General Psychiatry 1994;51(4):273-9.

25. Hensala JD, Epstein LJ, Blacker KH. LSD and psychiatric inpatients. Archives of General Psychiatry 1967;16(5):554-9.

26. Siris SG. Commentary, substance abuse in schizophrenia. The Journal of Nervous and Mental Disease 1992;180:5956.

27. Chambers RA, Krystal JH, Self DW. A neurobiological basis for substance abuse co-morbidity an schizophrenia. Biological Psychiatry 2001;50(2):71-83.

28. Khantzian EJ. The self-medication hypothesis of substance use disorders: a reconsideration and recent applications. Harv Rev Psychiatry 1997;4(5):231-44.

29. Schneier FR, Siris SG. A review of psychoactive substance use and abuse in schizophrenia. Patterns of drug choice. Journal of Nervous and Mental Disease 1987;175(11): 641-52.

30. Baigent M, Holme G, Hafner RJ. Self reports of the interaction between substance abuse and schizophrenia. Australian and New Zealand Journal of Psychiatry 1995;29(1):69-74.

31. Knudsen P, Vilmar T. Cannabis and neuroleptic agents in schizophrenia. Acta Psychiatrica Scandinavica 1984;69(2):162-74.

32. Paul L, Morris B, Beam-Gaulet J, et al. Relationship of positive and negative symptoms to cocaine abuse in schizophrenia. Journal of Nervous and Mental Disease 1994;182(2):109-12.

33. Castaneda R, Lifshutz H, Galantar M, et al. Empirical assessment of the self-medication hypothesis among dually diagnosed inpatients. Comprehensive Psychiatry 1994;35(3):180-4.
34. Fishman MW, Schuster CR, Resnekov L, et al. Cardiovascular and subjective effects of intravascular cocaine administration in humans. Archives of General Psychiatry 1976;33(8):983-9.

35. Drake RE, Wallach MA. Substance abuse among the chronic mentally ill. Hospital and community psychiatry 1989;40(10):1041-6.

36. Mueser KT, Yarnold PR, Levinson DF, et al. Prevalence of substance abuse in schizophrenia: demographic and clinical correlates. Schizophrenia Bulletin 1990;16(1):3156.

37. Dixon L, Haas G, Weiden PJ, et al. Drug abuse in schizophrenic patients: clinical correlates and reasons for use. American Journal of Psychiatry 1991;148(2):224-30.

38. Fowler IL, Carr VJ, Carter NT, et al. Patterns of current and lifetime substance use in schizophrenia. Schizophrenia Bulletin 1998;24(3):443-55.

39. Addington J, Addington D. Substance abuse and cognitive functioning in schizophrenia. Journal of Psychiatry and Neuroscience 1997;22(2):99-104.

40. Dixon L. Dual diagnosis of substance abuse in schizophrenia: prevalence and impact on outcomes. Schizophrenia Research 1999;35 Suppl:S93-S100.

41. Swofford CD, Scheller-Gilkey G, Miller AH, et al. Double jeopardy: schizophrenia and substance use. American Journal of Drug and Alcohol Abuse 2000;26(3):343-53.

42. Saylers MP, Mueser KT. Social functioning, psychopathology, and medication side effects in relation to substance use and abuse in schizophrenia. Schizophrenia Research 2001;48(1):109-23.

43. Cleghorn JM, Kaplan RD, Szechtman B, et al. Substance abuse and schizophrenia: effects of symptoms, but not on neurocognitive function. Journal of Clinical Psychiatry 1991;52(1):26-30.

44. Patkar AA, Alexander RC, Lundy A, et al. Changing patterns of illicit substance use among schizophrenic patients: 1984-1996. American Journal on Addictions 1999;8(1): 65-71.

45. Miller FT, Busch F, Tanenbaum JH. Drug abuse in schizophrenia. Am J Drug Alcohol Abuse 1989;15(3): 291-5.

46. Castaneda R, Galanter M, Lifshutz H, et al. Effects of drugs of abuse on psychiatric symptoms among hospitalised schizophrenics. Am J Drug Alcohol Abuse 1991;17(3): 313-20. 